\title{
Potential Risks Associated with Medication Administration, as Identified by Simple Tools and Observations
}

\author{
Adrian Ghenadenik, Élise Rochais, Suzanne Atkinson, and Jean-François Bussières
}

\section{INTRODUCTION}

A dverse events are common in health care institutions. In a study published in 2007, the Canadian Institute for Health Information reported that " 1 in 13 adult medical and surgical patients admitted to acute care hospitals in Canada in 2000 experienced an adverse event". ${ }^{1}$ Medication errors are among the most frequent adverse events. In an international survey of adults with health problems, administered by The Commonwealth Fund, about 10\% of Canadian respondents reported having received the wrong medication or dose from a health care provider in the previous 2 years. ${ }^{2}$ These errors may result in morbidity, mortality, increases in monitoring and costs of care, and delays in hospital discharge.

A prospective cohort study analyzing the incidence of drug-related adverse events in 2 tertiary care hospitals showed that $34 \%$ of preventable adverse medication-related events were at the administration stage, making this category the second most frequent cause (after errors at the ordering stage, which accounted for $56 \%$ of preventable adverse medication events). ${ }^{3}$

Given this reality, the management of medication-related risks is a priority for hospitals. The medication-use system is complex, with a total of 54 identified phases, ${ }^{4}$ for which many activities, tools, equipment, and information systems are needed and for which several interfaces are typically required. Many of these phases, particularly the medication administration process, carry high risks. Typically, nurses are responsible for the critical stages of the medication-use system, with a risk of error at each stage. Importantly, there seems to be a link between the way nurses' work is organized and the occurrence of errors during the administration of medications.

According to a study on nurses' perceptions of medication errors, "a single hospital patient can receive up to 18 medications per day, and a nurse can administer as many as 50 medications per working shift". 5 A study of the delivery of nursing care in acute care settings showed that nurses spent
$16 \%$ of their time preparing or administering medications. ${ }^{6}$ In addition, $22 \%$ of interruptions occurred during the medication preparation process. ${ }^{6} \mathrm{~A}$ high number of interruptions can lead to medication errors.

At the authors' centre, medication errors were an important cause of incidents and accidents from 2004 to 2010 . $^{7}$ More specifically, medication errors represented $74 \%$ of incidents and accidents in 2004/2005, although this proportion was reduced to $39 \%$ in $2010 / 2011$. Errors related to drug administration represented $66.3 \%$ of these medication errors. ${ }^{7}$

Various preventive strategies are used to manage risk within the medication-use system, including training and use of daily unit-dose medication distribution systems, with medication carts containing individual drawers designated for specific patients (identified by bed numbers). Nonetheless, errors still occur frequently in health care institutions.

\section{METHODS}

To identify potential sources of risk within the medication administration process and to propose corrective actions, an observational study was conducted between February and April 2011 in a 500-bed mother and child hospital in Montréal, Quebec.

The study consisted of the following 4 phases: (1) specific description of the medication administration process, including its inputs, outputs, resources, and control mechanisms; (2) representation of the process using a flow chart; (3) observational audit of the process; and (4) analysis of the results and development of recommendations. This approach was chosen over other methods, such as failure mode and effects analysis, as it allows detection of nonconformities in "real-life" practice, which can then be addressed with corrective actions.

The study was conducted in the Multispecialty and Transplant units of the study institution, which had a total capacity of 38 beds and a monthly average of 20000 doses 


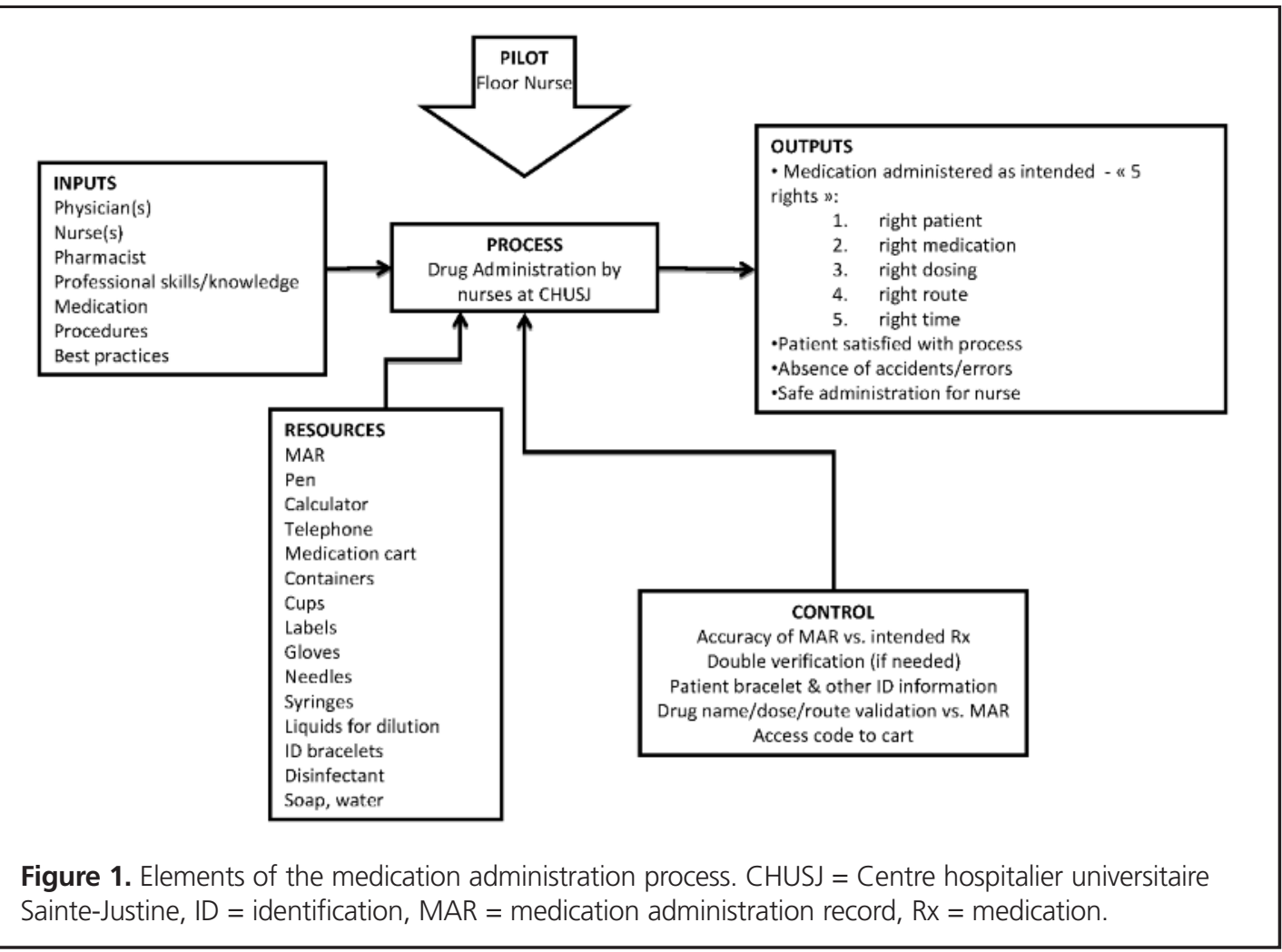

administered to patients. Each ward was equipped with multiple medication carts containing individual drawers, identified according to patients' bed numbers. In most cases, medications were supplied by the hospital's central pharmacy in individual doses. Some frequently used medications were also available in the floor stock storage area.

Observations were conducted over a period of 3 consecutive days. Data collection was performed by 2 research assistants (A.G., E.R.), who followed nurses step by step when a dose of medication was to be administered and noted each action performed. Once these observations had been gathered, the frequency of compliance with policies and procedures was determined and analyzed for each individual action within the medication administration process. A process improvement session involving the 2 research assistants (A.G., E.R.), a pharmacist (S.A.), and a nurse was then convened, with the objective of exploring potential interventions that could improve the medication administration process. The Hanlon method, also called the Basic Priority Rating model, ${ }^{8}$ was then used to prioritize areas of concern about nurses' actions during the medication administration process. This indirect evaluation technique allows researchers to organize issues of concern into groups that are weighted relative to each other and thus to generate a list of priorities based on 4 criteria: the size of the problem, the seriousness of the problem, the effectiveness of a potential intervention, and the feasibility of the intervention. No statistical analyses were performed.

\section{RESULTS}

During the observational analysis, 7 inputs, 15 resources, 5 controls, and 4 outputs were identified for the medication administration process (Figure 1). This information was used to develop a medication administration flow chart (Figure 2). A total of 29 documented observations were generated by the observational audit of the medication administration process and identification of nonconformities with existing policies and procedures (Figure 3).

Overall, the medication administration processes, as performed by the nurses and observed by the research assistants, were consistent with (i.e., conformed with) the actions and decisions outlined in the predefined process flow chart (as shown in Figure 2). In general, the actions and decisions commonly recognized as carrying a high risk were performed according to policy, including validating the written prescription against the prescription documented in the MAR, checking the accuracy and completion of documentation in the MAR in relation to the prescription, validating the name and dose of the drug and the route of administration, and preparing the medication and labelling it with the appropriate patient identifiers (e.g., name, room number, and patient's file number).

Conversely, the following actions, which might not necessarily be perceived as adding value, were consistently not performed, in spite of (in most cases) explicit policies and procedures: cleaning the surface of the medication cart; putting 


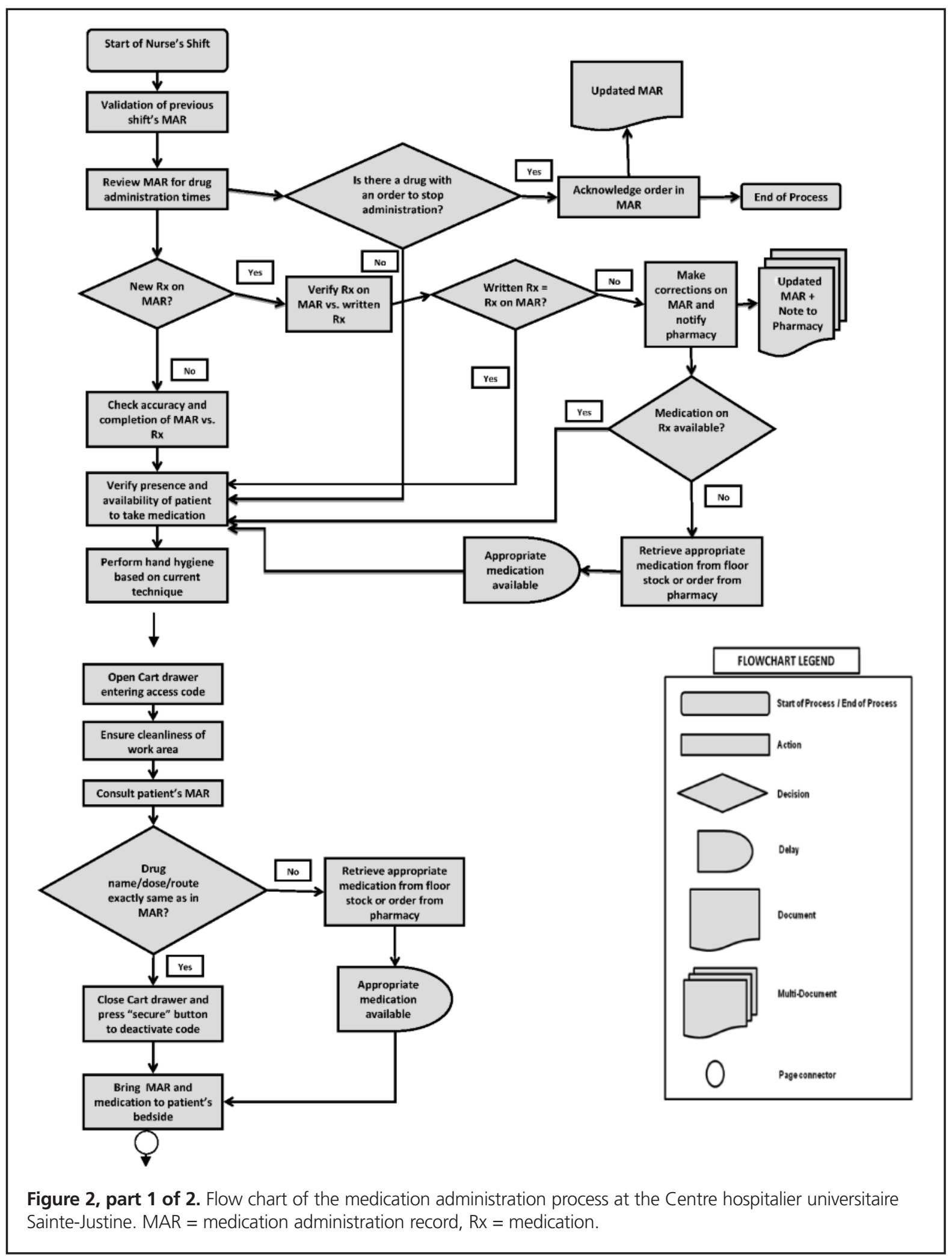




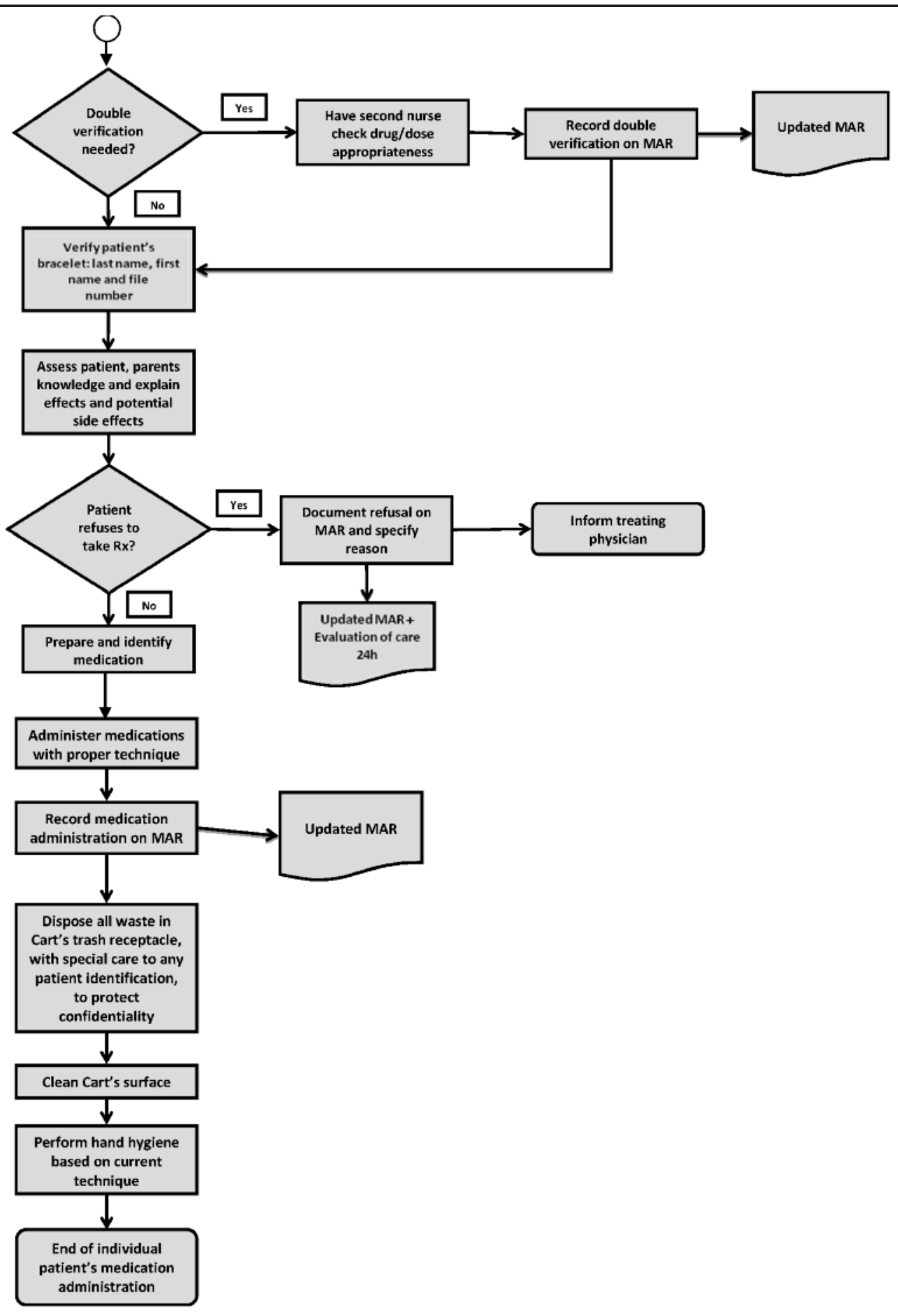

Figure 2, part $\mathbf{2}$ of $\mathbf{2}$. Flow chart of the medication administration process at the Centre hospitalier universitaire Sainte-Justine. MAR = medication administration record, $R x=$ medication.

all waste into the cart's trash receptacle as it was generated, with special attention to anything carrying the patient's identity (to protect confidentiality); bringing the MAR and the medication to the patient's bedside; verifying the patient's identification bracelet, with regard to last name, first name, and patient number; closing the cart drawer and pressing the "secure" button to deactivate the code; and ensuring cleanliness of the work area.

Finally, the audit showed that the following actions were sometimes not performed in conformity with policies and procedures: hand hygiene according to prescribed technique, both before and after medication administration; verification of patient's presence and availability to take the medication; and 


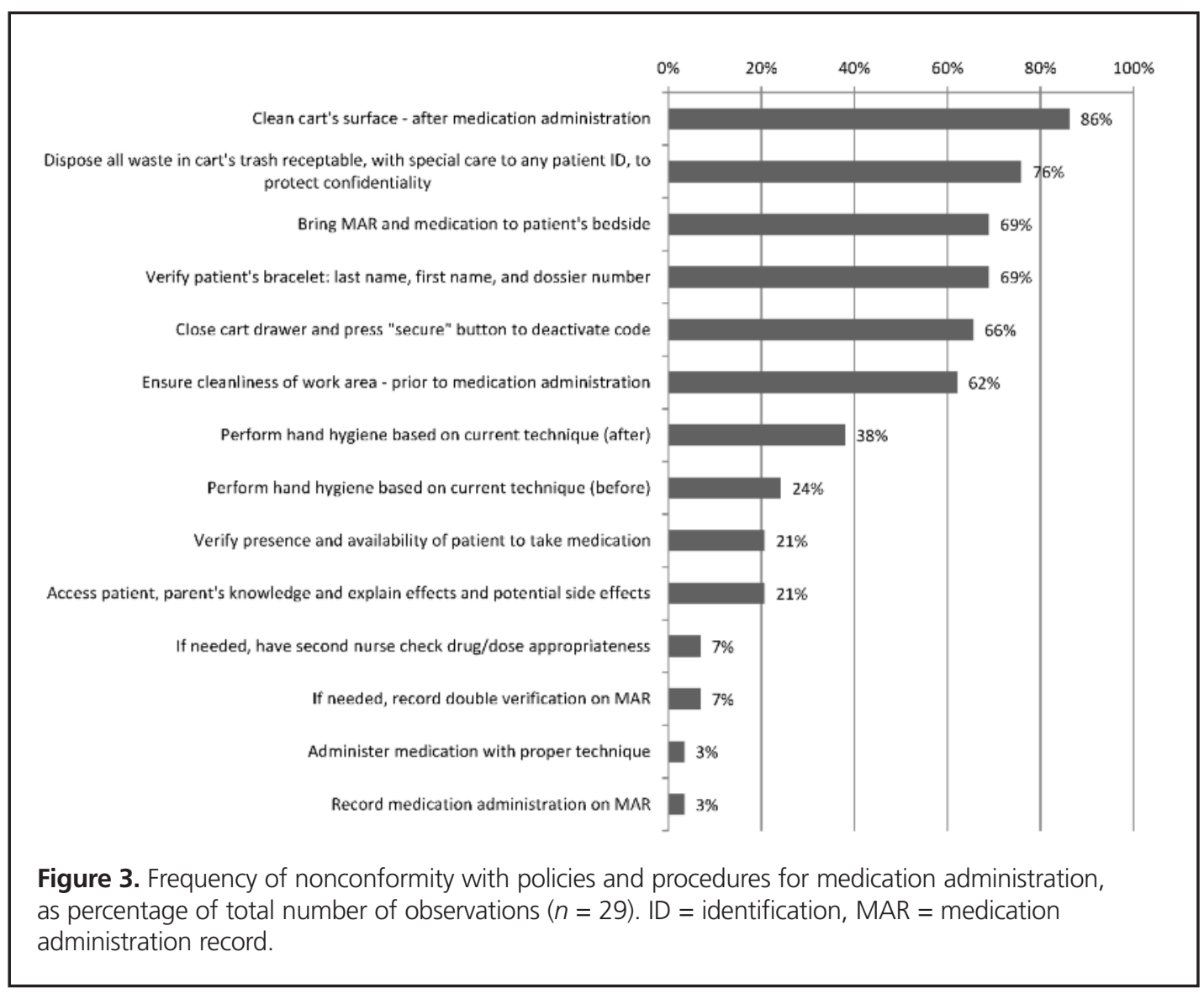

description and explanation of the effects and potential side effects of the medication.

Some of the actions that were consistently or sometimes not performed may represent potential concerns, in particular those directly linked to patient safety.

The process improvement session, which took place after the observational process audit, involved the following steps: presentation of audit results to the team; clarification of issues of concern, using input from all team members; preparation of an affinity diagram (a tool used to identify and address a variety of issues simultaneously, by structuring and classifying them $^{9}$ ) (Figure 4); grouping of observed nonconformities by type; and development of a prioritization exercise to help determine which nonconformities should be addressed first.

The prioritization exercise was based on the Hanlon method, which objectively takes into consideration explicitly defined criteria and feasibility factors. ${ }^{8}$ As a result of this exercise, 3 nonconformities were considered to be high-priority issues, 2 nonconformities were deemed important but of lower priority, and the rest were considered nonpriority issues (Table 1).

The 3 issues evaluated as having the top priority (i.e., requiring prompt intervention) were neglecting to close the cart drawer and press the "secure" button to deactivate the access code, neglecting to dispose of all waste in the cart's trash recep- tacle as it was generated, and failing to bring the MAR to the patient's bedside. Closing the cart drawer and deactivating the code are important because carts are located in ward hallways, where patients, parents, and other unauthorized persons could gain access to medications and supplies in the carts. It was therefore agreed that this issue had to be addressed immediately, because of the safety risk. The relative simplicity of the solution and the feasibility of its implementation resulted in the highest priority score for this issue (Table 1). The need to dispose of all waste in the cart's trash receptacle was a priority because omitting this step occurred frequently and was associated with a risk of breaching patient confidentiality. Again, the solution seemed relatively simple and feasible to implement. Failure to bring the MAR to the patient's bedside entails a risk of error in one or more of the " 5 rights" of medication administration (right medication, right dose, right patient, right time, right route).

\section{DISCUSSION}

This observational study allowed identification of 5 priority issues of concern (3 "high-priority" issues and 2 "important" issues) in the medication administration process at the authors' centre. Most of these issues were linked to the use of medication carts. As a major factor in nurses' environment, 


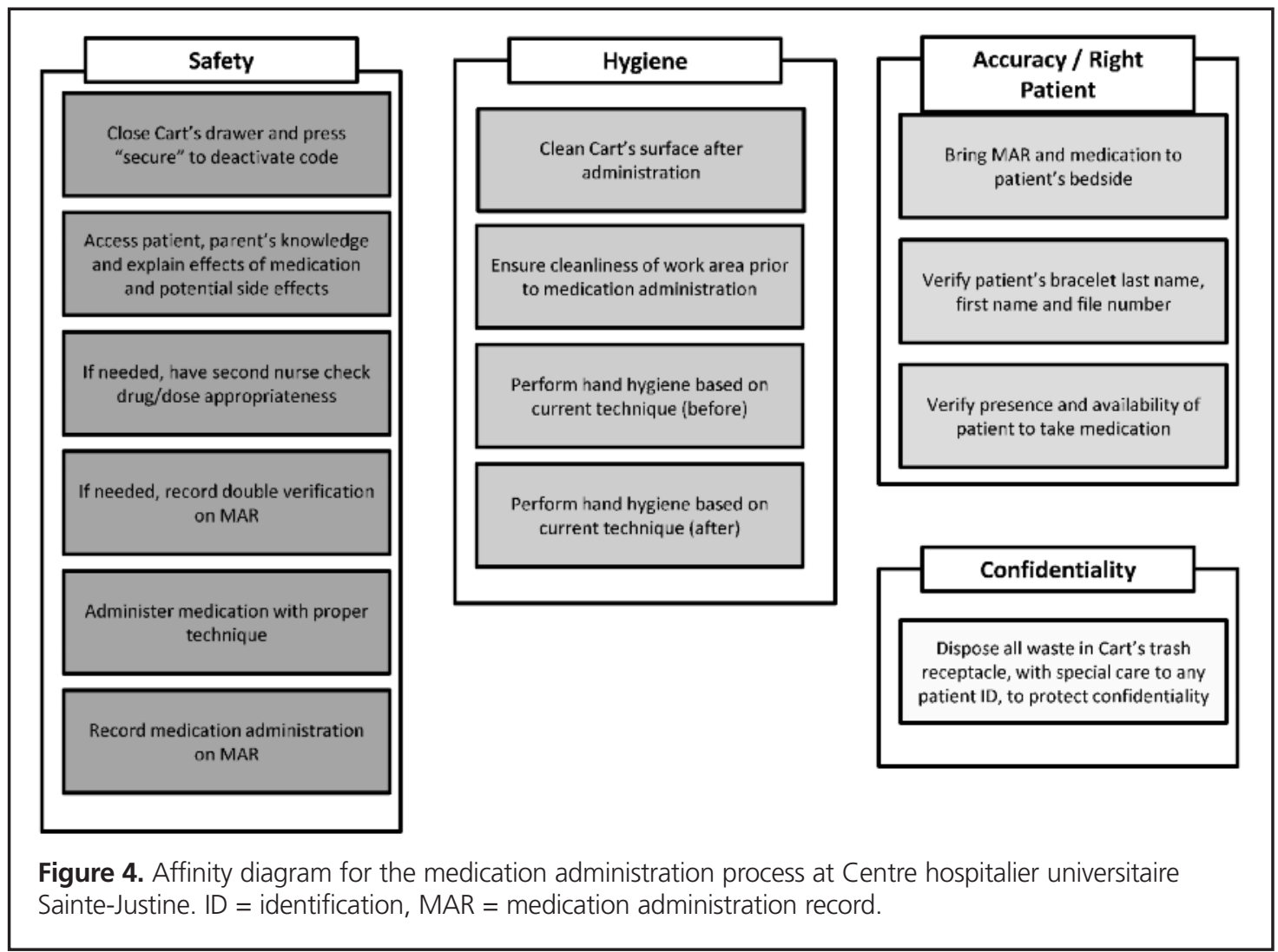

medication carts are involved in the safety of administering medications. For nurses, the carts provide accessibility of unitdose and frequently used medications at a location close to the patient. They also provide a work area for planning the administration of medications. However, their use also involves some disadvantages, including frequent interruptions (because the carts are located in ward corridors), the need for nurses to travel significant distances during the medication administration process (because other medications, such as narcotics, are kept in the ward pharmacy), relative ease of access to medications by unauthorized persons (if the cart is not locked after each opening), and the potential for confusion and error when several nurses need to access drawers on one cart at the same time.

Two of the 3 high-priority issues identified in this study (closing drawers and disposing of waste) could be addressed relatively easily through information sessions for staff and posting of memos in work areas. As for the third high-priority issue, bringing the MAR to the patient's bedside, it was originally thought that introducing medication carts would encourage this behaviour, but the observational audit indicated otherwise. In conjunction with other actions, such as verifying the patient's presence and availability to take the medication, verifying the patient's identity, and performing double verification for high-risk medications, bringing the MAR to the patient's bedside is a way of ensuring that the " 5 rights" are in place before administering a medication. Assigning an individual mobile cart to each nurse, with the assigned cart having medication drawers for only that nurse's patients, might encourage use of the MAR at the bedside. However, this option would be costly and is subject to various limitations (e.g., would not be feasible for patients who are in isolation because of infection).

From the point of view of pharmacists and health care management staff, absence of double verification of the patient's identify is a concern, although it did not emerge as a priority issue in this analysis. Double verification of the patient's identity is an important aspect of ensuring the safety of the medication administration process, because it can prevent a medication being given to the wrong patient, an error that could cause significant damage to patients' health. Importantly, double verification of patient identity before administering a medication is a Required Organizational Practice within Accreditation Canada's Managing Medication standard..$^{10}$ Most of the patients in the 2 units observed in this study were receiving acute care and had a longer-than-average stay in hospital; as such, the nurses usually knew them well. It would be interesting to perform a similar analysis in patient care units with a shorter mean length of stay or with young patients who are not yet able to talk. 
This single copy is for your personal, non-commercial use only.

For permission to reprint multiple copies or to order presentation-ready copies for distribution, contact CJHP at cjhpedit@cshp.ca

Table 1. Prioritization of Issues Using Hanlon's Method

\begin{tabular}{|c|c|c|c|c|c|}
\hline Issue & $\begin{array}{l}\text { Size of Problem } \\
(1-10)(A)\end{array}$ & $\begin{array}{l}\text { Seriousness of } \\
\text { Problem } \\
(1-10)(B)\end{array}$ & $\begin{array}{l}\text { Effectiveness } \\
\text { of Intervention } \\
(0.5-1.5)(C)\end{array}$ & $\begin{array}{l}\text { Feasibility of } \\
\text { Intervention } \\
(0 \text { or } 1)(D)\end{array}$ & $\begin{array}{l}\text { Priority Score } \\
(A+B) \times C \times D\end{array}$ \\
\hline \multicolumn{6}{|l|}{ High priority } \\
\hline $\begin{array}{l}\text { Close cart drawer and press } \\
\text { "secure" button to deactivate code }\end{array}$ & 7 & 10 & 1.5 & 1 & 25.5 \\
\hline $\begin{array}{l}\text { Dispose of all waste in cart's trash } \\
\text { receptacle as it is generated, with } \\
\text { special attention to any patient ID } \\
\text { (to protect confidentiality) }\end{array}$ & 8 & 7 & 1.5 & 1 & 22.5 \\
\hline $\begin{array}{l}\text { Bring MAR and medication to } \\
\text { patient's bedside }\end{array}$ & 7 & 10 & 1.0 & 1 & 17.0 \\
\hline \multicolumn{6}{|l|}{ Important } \\
\hline $\begin{array}{l}\text { Ensure cleanliness of work area } \\
\text { (before medication administration) }\end{array}$ & 6 & 9 & 1.0 & 1 & 15.0 \\
\hline $\begin{array}{l}\text { Clean cart's surface } \\
\text { (after medication administration) }\end{array}$ & 9 & 5 & 1.0 & 1 & 14.0 \\
\hline \multicolumn{6}{|l|}{ Nonpriority } \\
\hline $\begin{array}{l}\text { Administer medication with } \\
\text { proper technique }\end{array}$ & 1 & 8 & 1.0 & 1 & 9.0 \\
\hline $\begin{array}{l}\text { Record administration of medication } \\
\text { in MAR }\end{array}$ & 1 & 8 & 1.0 & 1 & 9.0 \\
\hline $\begin{array}{l}\text { If needed, have second nurse check } \\
\text { drug/dose appropriateness }\end{array}$ & 1 & 8 & 1.0 & 1 & 9.0 \\
\hline $\begin{array}{l}\text { If needed, record double verification } \\
\text { in MAR }\end{array}$ & 1 & 8 & 1.0 & 1 & 9.0 \\
\hline $\begin{array}{l}\text { Perform hand hygiene according to } \\
\text { current technique (before } \\
\text { medication administration) }\end{array}$ & 3 & 8 & 0.5 & 1 & 5.5 \\
\hline $\begin{array}{l}\text { Perform hand hygiene according to } \\
\text { current technique (after } \\
\text { medication administration) }\end{array}$ & 4 & 7 & 0.5 & 1 & 5.5 \\
\hline $\begin{array}{l}\text { Verify patient's bracelet: last name, } \\
\text { first name, file number }\end{array}$ & 7 & 6 & 1.0 & 0 & 0.0 \\
\hline $\begin{array}{l}\text { Verify presence and availability of } \\
\text { patient to take medication }\end{array}$ & 2 & 1 & 0.5 & 0 & 0.0 \\
\hline $\begin{array}{l}\text { Determine patient's and/or parent's } \\
\text { level of knowledge; explain effects } \\
\text { of medication and potential } \\
\text { side effects }\end{array}$ & 2 & 5 & 0.5 & 0 & 0.0 \\
\hline
\end{tabular}

$\mathrm{ID}=$ identification, $\mathrm{MAR}=$ medication administration record.

The 2 identified issues that were classified as important were related to maintenance of the cart: ensuring cleanliness of the work area before medication administration and cleaning the cart's surface afterward. A review of the policies and procedures for cart maintenance is probably necessary to address these important issues and to ensure that medications are prepared on surfaces that are as clean as possible. The analysis also showed how nurses' working conditions (especially those related to medication carts or other medication distribution systems) affect potential risks in medication-use processes.

For this observational study, a different approach was used than in previous studies conducted in the same institution. ${ }^{7,11,12}$ Although the number of observations was limited $(n=29)$, it was sufficient for the chosen method of analysis. An important limitation of the study was the fact that it was conducted in only one type of patient care unit (as represented by the Multispecialty and Transplant units); further observations in other types of health care units are required to confirm the generalizability of this method of analysis. The priority issues identified in other units would likely be different, especially in units with a different physical layout. Another important limitation is related to the use of observational techniques. In particular, it was difficult to follow and observe nurses from the beginning to the end of a single task, because they were frequently interrupted. In addition, there was a potential for bias because the nurses were more aware of the need to follow proper procedures as a result of being followed by observers. 


\section{CONCLUSIONS}

Managing risks related to the medication administration process is of utmost importance, and many approaches are currently used to achieve this objective. Given the complexity of the medication-use system, it is important to propose tools that do not require a significant investment of resources, in terms of time, knowledge, or personnel. This study has shown that relatively simple tools, combined with careful observation, can be effective in identifying potential risks and proposing corrective actions. The only requirements for using this approach are an individual with reasonable knowledge of process-evaluation tools and strong collaboration and commitment from all of the stakeholders involved with regard to the evaluation, analysis of results, and implementation of new processes. Consistent application of process-evaluation tools can be useful in reducing the risks associated with the medication-use system. Therefore, sustained effort in the development and application of such approaches should be instrumental in the continuous improvement of quality in health care organizations.

References

1. Patient safety in Canada: an update 2007. Ottawa (ON): Canadian Institute for Health Information; 2007 [cited 2012 Jan 31]. p. 2. Available from: http://secure.cihi.ca/cihiweb/products/Patient Safety AIB EN 070814.pdf

2. Section 900: medical error/safety issues. In: 2005 Commonwealth Fund international health policy survey of sicker adults. New York (NY): The Commonwealth Fund; 2005 Jun [cited 2012 Jan 31]. p. 15-16. Available from: www.commonwealthfund.org/Surveys/2005/2005-CommonwealthFund-International-Health-Policy-Survey-of-Sicker-Adults.aspx

3. Bates DW, Cullen DJ, Laird N, Petersen LA, Small SD, Servi D, et al Incidence of adverse drug events and potential adverse drug events. Implications for prevention. ADE Prevention Study Group. JAMA 1995;274(1):29-34.

4. Bussières, JF, Lebel D, Voytenko S, Vaquer G. Développement d'un concept et d'un processus de gestion de l'identité numérique d'un produit en établissement de santé. Can J Hosp Pharm 2009;62(5):409-414.

5. Mayo AM, Duncan D. Nurse perceptions of medication errors: what we need to know for patient safety. J Nurs Care Qual 2004;19(3):209-217.
6. Potter P, Wolf L, Boxerman S, Grayson D, Sledge J, Dunagan C, et al. Understanding the cognitive work of nursing in the acute care environment. J Nurs Admin 2005;35(7-8):327-335.

7. Rochais E, Lebel D, Atkinson S, Rocheleau L, Bussières JF. Perspectives sur les incidents et accidents médicamenteux en centre hospitalier universitaire. Risques Qual 2011;8(4):243-252.

8. Pickett GE, Hanlon JJ. Public health: administration and practice. 9th ed. Times Mirror/Mosby College Publisher; 1990.

9. Méthodes et outils des démarches qualité pour les établissements de santé. Paris (France): Agence nationale d'accréditation et d'évaluation en santé; 2000 [cited 2012 Apr 5]. Available from: www.has-sante.fr/portail/upload/ docs/application/pdf/2009-10/methodes.pdf

10. Required organizational practices 2012. Ottawa (ON): Accreditation Canada; 2011 Sep [cited 2012 Apr 5]. Available from: www.accreditation.ca/ uploadedFiles/ROP\%20Handbook.pdf

11. Alemanni J, Touzin K, Bussières JF, Descoteaux R, Lemay M. An assessment of drug administration compliance in a university hospita center. J Eval Clin Pract 2010;16(5):920-926.

12. Alemanni J, Bussières JF, Genest C, Pelchat V. Profil de l'utilisation de chariots de médicaments en courte durée et perspective sur leur utilisation optimale. Pharmactuel 2010;43(2):108-116.

Adrian Ghenadenik, BComm, is a candidate for a Master's in Health Administration at the Université de Montreal, Montréal, Quebec. He is also a Research Assistant with the Pharmacy Practice Research Unit, CHU Sainte-Justine, Montréal, Quebec.

Élise Rochais is a DPharm student at Université Paris Descartes, Paris, France. She is also a Research Assistant with the Pharmacy Practice Research Unit, CHU Sainte-Justine, Montréal, Quebec.

Suzanne Atkinson, BPharm, MSc, DESS, is Assistant Director, Pharmacy Services, Pharmacy Department, CHU Sainte-Justine, Montréal, Quebec.

Jean-François Bussières, BPharm, MSC, FCSHP, is Head of the Pharmacy Department and the Pharmacy Practice Research Unit, CHU Sainte-Justine, and Clinical Professor, Faculty of Pharmacy, Université de Montréal, Montréal, Quebec.

Address correspondence to:

Jean-François Bussières

Pharmacy Department

Centre hospitalier universitaire Sainte-Justine

3175, chemin de la Côte Sainte-Catherine

Montréal QC H3T 1C5

e-mail: jf.bussieres@ssss.gouv.qc.ca 